Bull. Mater. Sci., Vol. 2, Number 1, January 1980, pp. 17-29. (C) Printed in India

\title{
Production and characterisation of amorphous alloys at Varanasi *
}

\author{
P RAMACHANDRARAO, S RANGANATHAN and \\ T R ANANTHARAMAN \\ Department of Metallurgical Engineering and School of Materials Science and \\ Technology, Banaras Hindu University, Varanasi 221005
}

MS received 23 October 1979

\begin{abstract}
Amorphous alloys, more commonly referred to as metallic glasses, represent a striking advance in inorganic materials technology of recent times. While the probable atomic arrangements in noncrystalline alloys have aroused scientific curiosity, their unusual mechanical strength, attractive magnetic properties and remarkable corrosion resistance have excited technological interest. This report describes the progress of research at Varanasi on the following aspects: adaptation, innovation and development of techniques for rapid solidification, study and refinement of structural models, calculation of thermodynamic quantities, evaluation of strength and corrosion resistance and studies of glass to crystal transition.
\end{abstract}

Keywords. Metallic glasses; amorphous alloys; rapid solidification; structural models; melt-spinning technique; piston-and-anvil technique; thermodynamics; devitrification phenomena.

\section{Introduction}

It is now just two decades since the first metallic glass was synthesised at the California Institute of Technology, Pasadena, USA (Duwez et al 1960) by rapid quenching of an Au-Si eutectic alloy melt containing 20 atom per cent (at \%) Si. It was a classical case of serendipity. However, interest in the field was dormant for over a decade, as the amounts of glasses produced by the original method were small. It was the introduction of techniques of continuous quenching from the liquid state leading to the production of wide and long ribbons of several metallic glasses that started an explosive growth of activity in this area during the seventies. Simultaneous recognition of the attractive mechanical, magnetic and chemical properties of the metallic glasses has now established this fascinating area of research and development as a major and perhaps the most signiffcant branch of physical metallurgy. Duwez (1979) and Anantharaman (1979) have recently reviewed these developments.

Research in rapid solidiffcation made a modest beginning at the Banaras Hindu University in 1966 follow'ng contacts with the Duwez group in the USA. For many years the major concern at Varanasi was the study of formation and properties of metastable solid solutions and intermediate phases in rapidly solidified alu-

\footnotetext{
* A brief report on the progress in research on metallic glasses of the Rapid Solidification group at the Banaras Hindu University, Varanasi.
} 
minium alloys (Anantharaman et al 1977; Anantharaman et al 1978). Since 1973 the interest has turned to amorphous alloys. Initial modest support for this effort came from the Indian National Science Academy (Ranganathan et al 1973). Since 1976 the Department of Science and Technology has extended generous support to a project in which many scientists including all the three authors of this report are actively involved. The following sections describe briefly the work done at Varanasi against the background of current international trends in this exciting field.

\section{Batch and bulk production}

The key to the production of metallic glasses is the achievement of high cooling rates and consequent drastic undercooling of metallic melts. A number of techniques are in vogue and are noted for their simplicity and elegance.

The original gun technique devised by Duwez and Willens (1963) offers many advantages for exploratory investigations. In this method a small quantity of melt, weighing $100-500 \mathrm{mg}$, is ejected by means of a shock wave, created by rupturing a mylar diaphragm with high pressure argon gas. The globule travels at a speed of $300 \mathrm{~m} \mathrm{sec}^{-1}$ and is splatted against an inclined copper substrate. Heat extraction by conduction is efficient and provides cooling rates of the order of $10^{6} \mathrm{~K} \mathrm{sec}^{-1}$. An adaptation of the Duwez design has been extensively used in Varanasi since 1966 (Ramachandrarao 1968). It has proved useful in producing thin foils (maximum thickness $\sim 30 \mu$ ) of glassy $\mathrm{Pb}-\mathrm{Sb}, \mathrm{Al}-\mathrm{Ni}$ and $\mathrm{Al}-\mathrm{Pd}$ alloys.

Another popular technique has been the piston-and-anvil technique (Pietrokowsky 1963), where the substrate is propelled at great speed against the melt. A drop of the molten alloy, ejected by slight gas pressure, intercepts a beam of light between a source and photocell. An adjustable delay circuit triggers the solenoid releasing the piston. The liquid droplet gets squeezed between a fixed anvil and the fast moving piston. Ramachandrarao et al (1970a) have ingeniously combined the gun and the piston-and-anvil techniques. Figure 1 is a line diagram of their

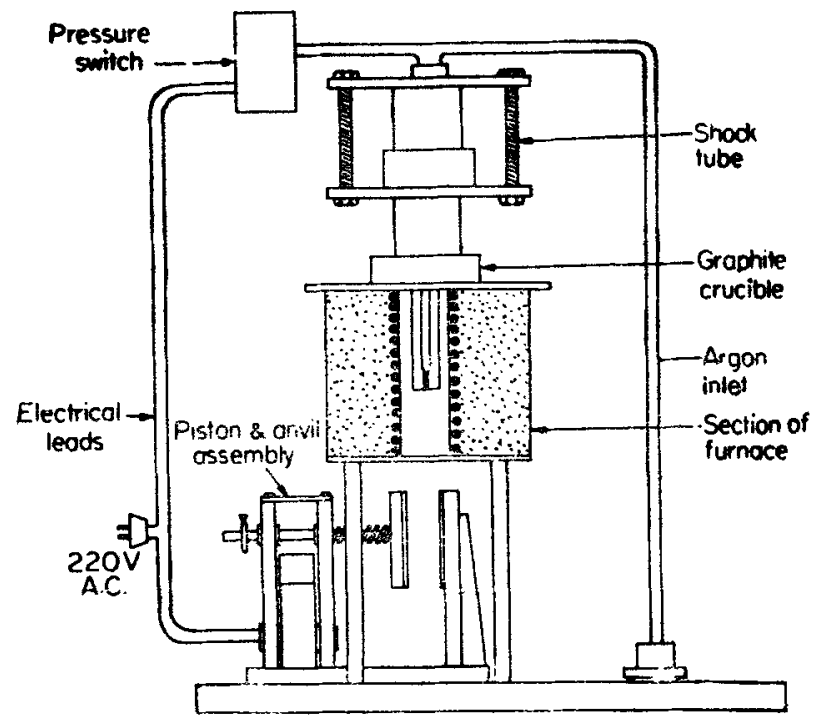

Figure 1. The combined gun and piston-and-anvil technique. 


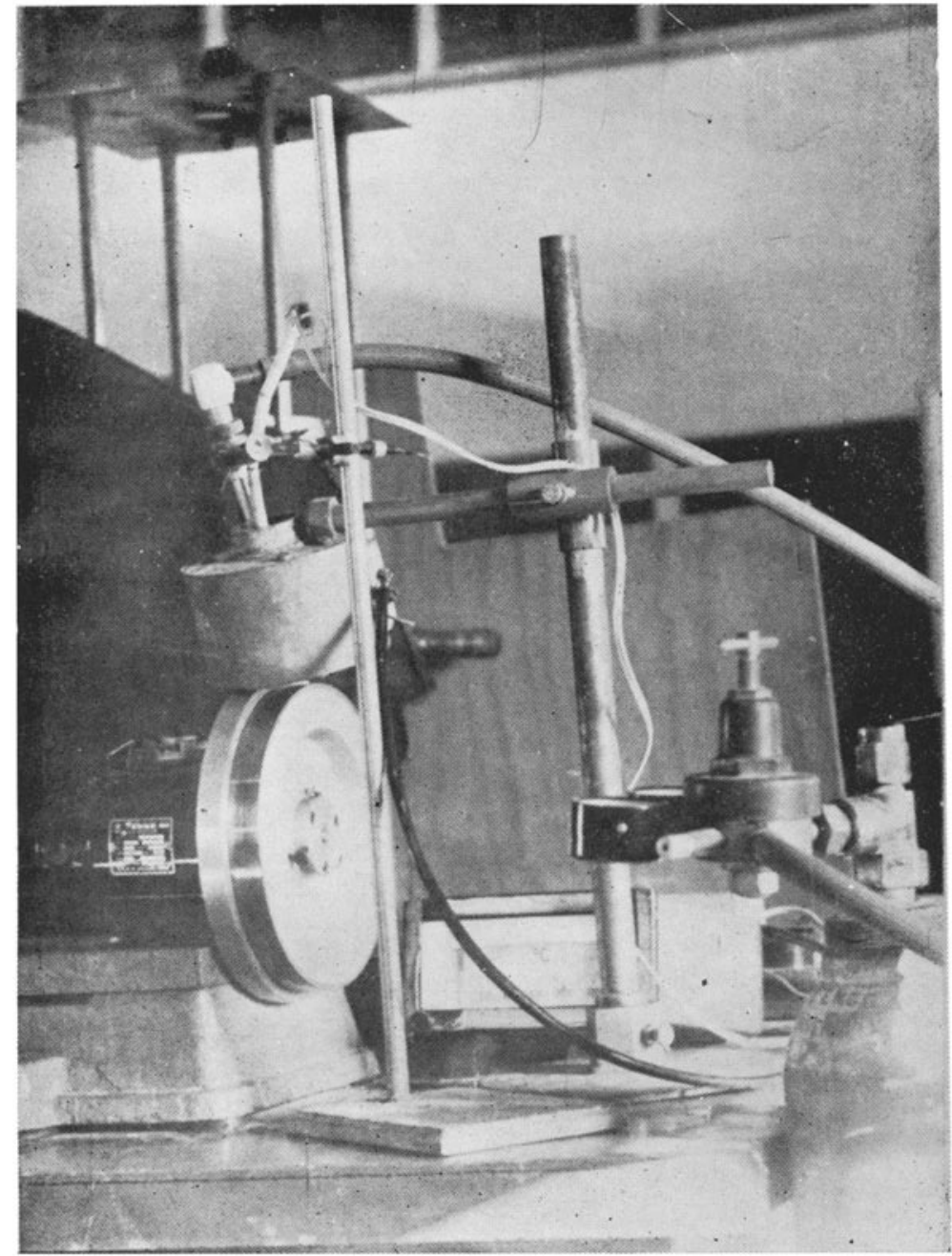

Figure 3. The melt-spinning apparatus. 
quenching apparatus. Instead of the photocell arrangement the triggering of the piston is coupled with the diaphragm rupture by the incorporation of a pressure switch. Large and circular foils (upto $5 \mathrm{~cm}$ dia) produced by this method are suitable for measurement of electrical and mechanical properties.

For bulk production of rapidly solidified metals, melt spinning and melt extraction (Hubert et al 1973; Maringer and Mobley 1974) have proved to be efficient and popular methods. A melt spinning unit has been built at Varanasi (Ramineni 1978). Figure 2 shows a line diagram of the apparatus, while figure 3 is a photograph of the unit. In this technique a pool of molten alloy comes into contact with a fast moving copper-lined dise and is spun into ribbons with a width of $5 \mathrm{~mm}$ and a thickness of $\sim 30 \mu$. The rotating speed of the disc, the shape and size of the orifice are all critical parameters to be adjusted for successful production of ribbons. It is hoped that somewhat broader and thicker ribbons will be produced in the near future following changes in design of the present unit.

While the above techniques are successful adaptations and modifications of methods developed elsewhere, Ramachandrarao et al (1979) have pioneered a novel technique for undercooling with promise for the production of metallic glasses. This involves quenching from the mushy state, consisting of a mixture of liquid and solid. The entrapped liquid undercools with heat absorption through the internal solid substrate. It has led to the production of metastable phases in $\mathrm{Al}-\mathrm{Ge}, \mathrm{Al}-\mathrm{Ni}, \mathrm{Ag}-\mathrm{Ge}$ and $\mathrm{Ag}-\mathrm{Cu}$ alloys. Its extension to the production of composites of crystalline and glassy phases will be of considerable interest.

\section{Atomic arrangements}

An early review on the structure of metallic glasses, written from Varanasi, offers a discussion of the various models for the atomic arrangements in amorphous alloys (Gokularathnam 1974). Among these Bernal's (1964) model for liquids based on a dense random assembly of hard spheres has found maximum adherents. A signi-

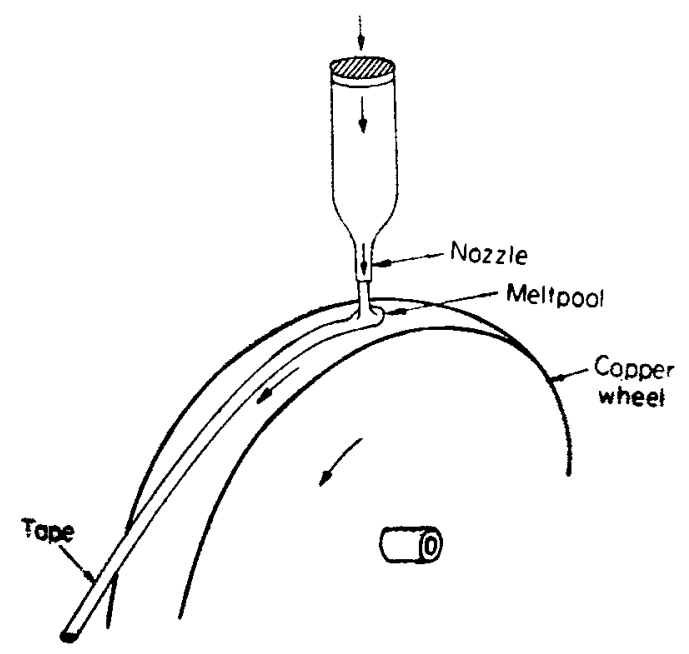

Figure 2. Principle of the melt-spinning technique. 
ficant feature of this model is the occurrence of polyhedral holes with atoms at the vertices. While the original model recognised five distinct types of holes, later extension (figure 4) has included eight types (Spaepen 1978). This model for a liquid has since been extrapolated to metallic glasses.

Considering the large family of metal-metalloid glasses, Polk (1970) assumed that the polyhedral holes formed by a random packing of metal atoms are natural sites for the smaller metalloid atoms. Since the relative proportion of metal atoms to holes is roughly 80 to 20 , this model leads to a natural and appealing explanation of the frequent occurrence of metal-metalloid glasses around a composition of 80 at. $\%$ metal. A number of stable glasses, however, do lie outside this composition and indeed many contain no metalloid, e.g. $\mathrm{Ni}_{60} \mathrm{Nb}_{40}$. Current models essentially extend the Bernal concept by taking into consideration the essential motif of tetrahedral packing of atoms. Many such groupings occur in the crystalline state of many intermetallic compounds. It appears that these groups are preserved in the glassy state as well, but without the long range periodicity characteristic of the crystalline state. These concepts are reminiscent of those applicable to silicate glasses with the $\mathrm{SiO}_{4}$ tetrahedra conserved and point to the pervading unity in divensity that nature accomplishes. However, as has been pointed out by Anantharaman (1979) recently, the current models do not satisfactorily explain all $x$-ray diffraction observations, particularly on thermal and mechanical treatment of the metallic glasses.

A related development is the problem of the structure of grain boundaries in metals. Early concepts that the boundaries may be amorphous or liquid-like gave way to an essentially crystallographic description of grain boundaries (Brandon et al 1964; Roy and Ranganathan 1976). However the recent observations of the ubiquitous occurrence of glassy phase in bulk in metals have provoked metallurgists to re-examine the area and apply the concept of random close packing to the strueture of grain boundaries (Ashby et al 1978). Extension of this model and a critical comparison with the crystallographic model is under preparation (Ranganathan 1979). A challenging and as yet, largely unexplored area for work is the nature of defects in amorphous alloys. Their enumeration and characterisation
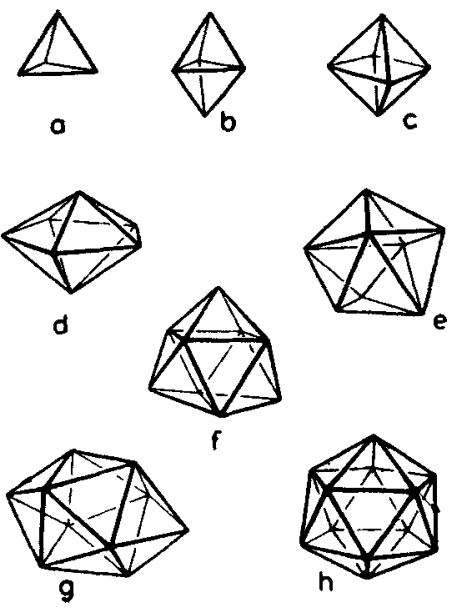

Figure 4. Convex deltahedra depicting voids in metallic glass (a) tetrahedron, (b) triangular dipyramid, (c) octahedron, (d) pentagonal dipyramid, (e) 12-hedron, (f) 14-hedron, (g) 16 hedron, (h) icosahedron. 
seem to be essential in understanding phenomena like diffusion, flow and fracture in them. Very little progress has been reported so far in this direction (Spaepen 1978).

\section{Thermodynamic investigations}

The atomistic and the thermodynamic approaches are comparable in the insight they provide for the study of amorphous alloys. A major contribution has been made by Ramachandrarao (1978, 1979a, 1979b) with the latter approach. An early contribution resulted by extending the ideas of hole and free volume theories of liquid to glasses (see figure 5, Ramachandrarao et al 1977). The formation energy of holes can be calculated by using experimental data on changes in speciftc heat, thermal expansion and temperature dependence of viscosity. It is postulated that transport in metallic glasses occurs by the movement of highly ionised ions. In many ways holes in glasses behave in a fashion comparable to that of vacancies in their crystalline counterparts. It is found that a linear relationship exists between the hole formation energy and the glass transition temperature. Suitable glasses can be synthesised by adjusting compositions towards enhanced hole energy.

Up till now conventional Yogel-Fulcher equations with three constants were used to represent the viscous behaviour of metallic glasses. It has been found that entirely different sets of constants are required to describe the viscous behaviour in the glassy state and at undercooling just below the normal melting point. The approach based on a combination of hole and free volume theories has led to the development of Doolittle-type equations for viscous behaviour of undercooled metallic melts. A single equation suffices to describe viscous behaviour over the entire temperature range of interest (Ramachandrarao et al 1977). This theory also provides physical significance to the constants in the Doolittle equation. This

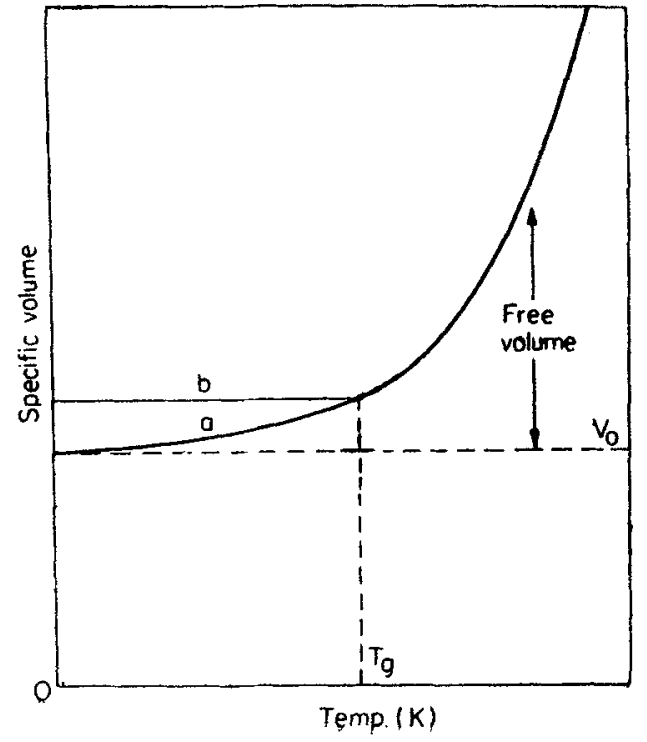

Figure 5. Schematic representation of the temperature dependence of free volume (a) in a liquid exhibiting no glass transition and (b) in a liquid undergoing glass transition at $\mathrm{Tg} . \mathrm{V}_{\theta}$ is the specific volume of the liquid at absolute zero temperature, 
has, in turn, enabled the use of viscoelastic models and viscosity data in estimating the cooling rate dependence of glass transition temperature. A knowledge of the fictive glass transition temperature has been shown to be of value in the estimation of heats of relaxation in metallic glasses (Ramachandrarao 1978). The constants in the Doolittle equation for viscosity could also be related to the heat of fusion of the alloy and the heat of crystallisation of the corresponding glass. This has opened up the possibility of obtaining viscosity equations from thermodynamic parameters (Ramachandrarao 1979a).

While a number of models have been proposed for the formation of metal-metalloid glasses, their occurrence in metal-metal systems is yet to receive satisfactory explanation (Nielsen 1979). In an attempt to tackle this problem a predictive approach based on the compositional dependence of strain energy of mixing liquid metals has been developed (Ramachandrarao 1979b). It has been shown that glass-forming compositions in binary metal-metal systems are invariably those corresponding to the least volume of the liquid alloy. This criterion has been tested in twentyfive systems and is found to be remarkably successful.

\section{Mechanical properties}

The mechanical properties of metallic glasses are characterised by extremely promising combinations of high strength and toughness. For example, $\mathrm{Fe}_{80} \mathrm{~B}_{20}$ has a yield strength of $370 \mathrm{~kg} / \mathrm{mm}^{2}$, an extensional modulus of $16.9 \times 10^{3} \mathrm{~kg} / \mathrm{mm}^{2}$ and a vickers hardness of $1100 \mathrm{~kg} / \mathrm{mm}^{2}$. It is stronger than the best carbon fibre. Flow in these alloys occurs in shear bands. Defects causing flow and fracture are under speculation.

Investigations on the effect of thermal neutron irradiation with flux of $3.2 \times 10^{6}$ neutrons $/ \mathrm{cm}^{2} / \mathrm{sec}$ on electrical resistivity and mechanical properties of METGLAS 2826 have been undertaken (Singh et al 1979). This material has the nominal composition $\mathrm{Fe}_{40} \mathrm{Ni}_{40} \mathrm{P}_{14} \mathrm{~B}_{6}$ and was obtained from Allied Chemical Corporation, Morristown, USA, a pioneering industrial establishment in this area. The specimens were irradiated for different lengths of time up to $300 \mathrm{~h}$ and annealed at room temperature prior to evaluation of their properties.

A related property is the environmental stability of metallic glasses. The corrosion rates of chromium-containing amorphous alloys have been reported to be orders of magnitude smaller than Fe-Cr alloys and 18-8 stainless steels (Masumoto et al 1978). At Varanasi, Singh and Namboodhiri (1979) have investigated the corrosion and stress corrosion cracking behaviour of METGLAS 2826. The corrosion behaviour of this alloy in $\mathrm{HCl}, \mathrm{H}_{2} \mathrm{SO}_{4}, \mathrm{FeCl}_{3}, \mathrm{NaCl}, \mathrm{NaOH}$ and $\mathrm{SO}_{2}$ environments was studied by total immersion tests followed by weight loss measurements. In $\mathrm{NaCl}$ and $\mathrm{NaOH}$ environments no corrosion could be detected even after exposure for 15 days. In $\mathrm{HCl}$ and $\mathrm{H}_{2} \mathrm{SO}_{4}$ media METGLAS 2826 was found to have a corrosion rate 30 times smaller than that of crystalline $\mathrm{Fe}-40 \% \mathrm{Ni}$ alloy. Pitting of the amorphous alloy takes place in $10 \% \mathrm{FeCl}_{3}$, while fogging occurs in the $\mathrm{SO}_{2}$ atmospheres. Constant strain rate tensile tests of notched as well as unnotched specimens were carried out in $\mathrm{HCl}$ and $\mathrm{H}_{2} \mathrm{SO}_{4}$ to determine the stress corrosion cracking susceptibility of METGLAS 2826. Figure 6 shows typical curves illustrating the variations in fracture stress and \% elongation with $\mathrm{HCl}$ concentration 


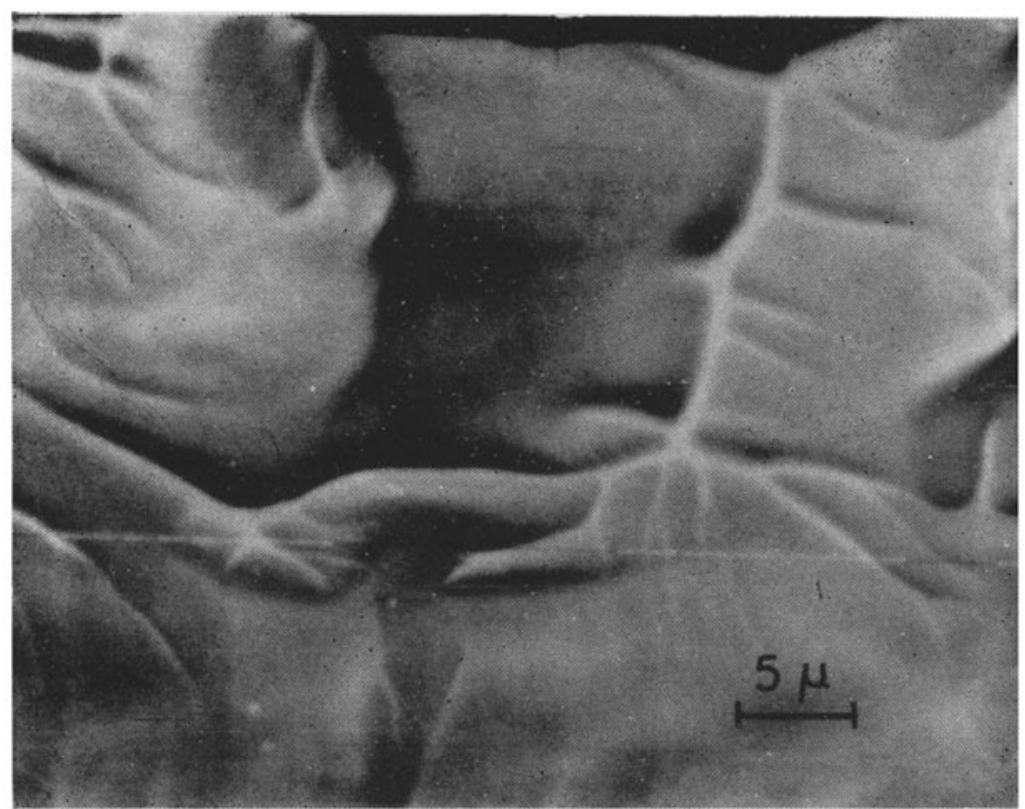

Figure 7. Scanning electron micrograph from fractured METGLAS 2826. Note. vein patterns. 

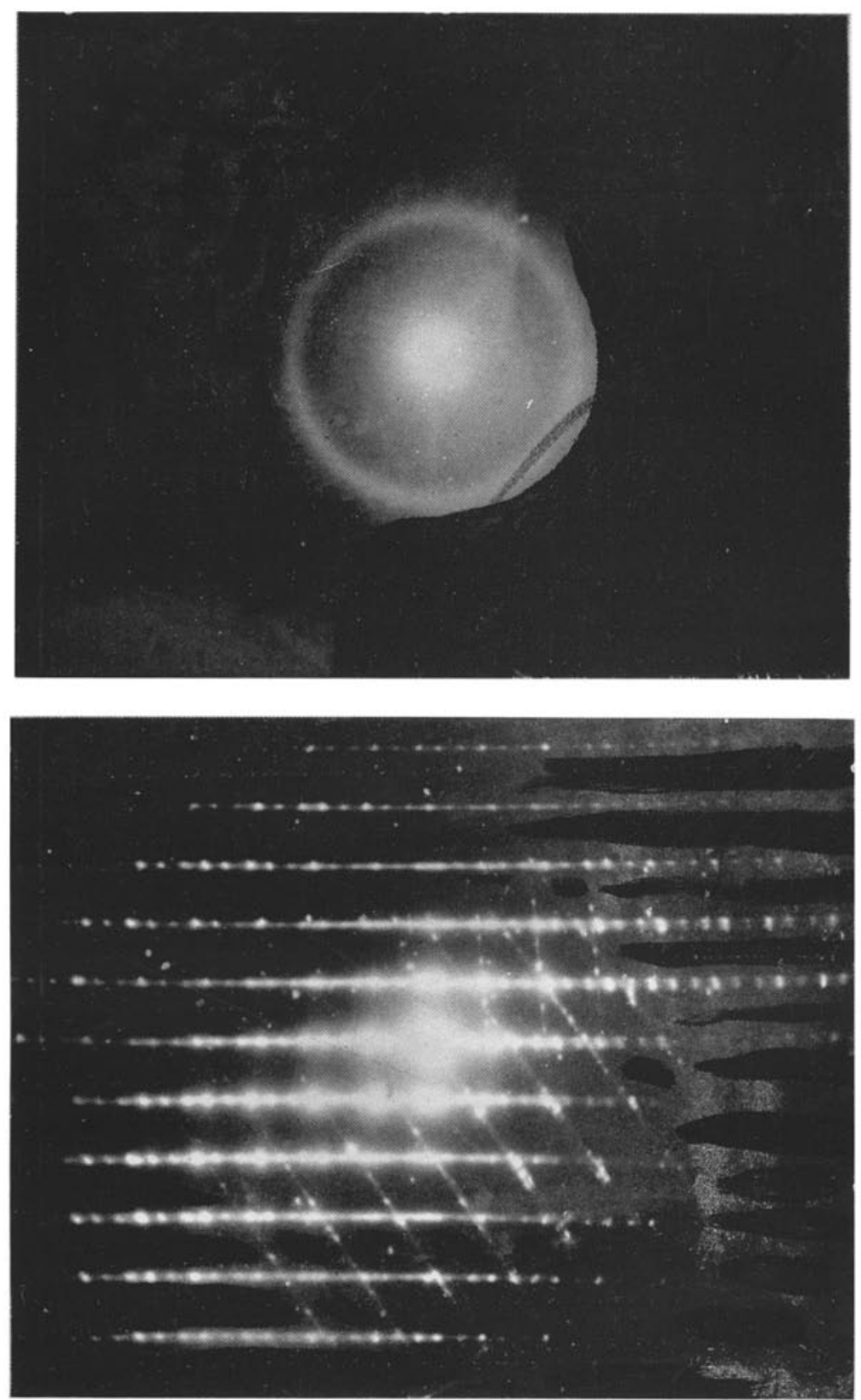

Figure 8 a. Electron diffraction pattern from amorphous nickel-niobium alloy. b. Pattern from the same alloy after crystallisation at $600^{\circ} \mathrm{C}$ for $1 \mathrm{~h}$. 


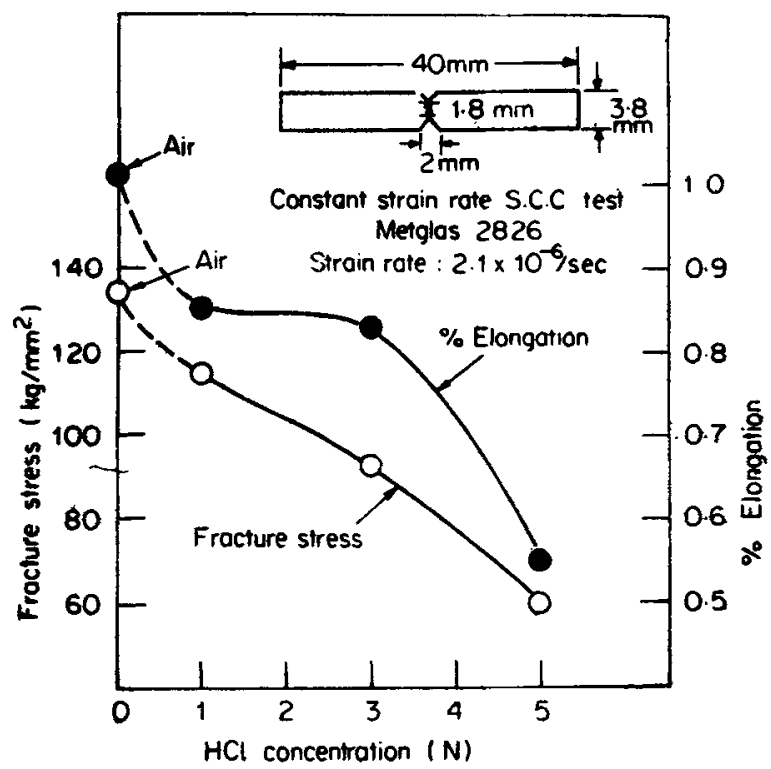

Figure 6. Constant strain rate stress corrosion cracking test of METGLAS 2826.

indicating the susceptibility of this material to stress corrosion cracking in acidic media. Fracture surface features were examined by scanning electron microscopy. Sharp vein patterns were seen (figure 7) in samples tested in air, but were less distinct in samples tested in corrosive media. These preliminary observations are being followed up with detailed electrochemical measurements to clarify the corrosion behaviour of amorphous alloys.

\section{Devitrification phenomena}

On heating, metallic glasses crystallise at sufficiently high temperatures. It is important to characterise the devitrification process in order to deftne the operating limits of metallic glasses. In addition, it may be possible to produce useful microstructures consisting of a mixture of glassy and crystalline phases by controlled decomposition of the amorphous alloy. Work done at Varanasi on crystallisation of four different glasses is described below.

Ramachandrarao et al (1970b) quenched a series of lead-antimony alloys containing up to $50 \%$ antimony. In the antimony-rich alloys, an amorphous phase was detected. On heating, this gave rise to a fine-grained mixture of equilibrium lead and antimony crystals.

Chattopadhyay et al (1976) have reported on the occurrence of an amorphous phase in an $\mathrm{Al}-7$ at. \% $\mathrm{Ni}$ alloy. This phase decomposed on beam heating inside the electron microscope into a mixture of aluminium solid solution and a non-equilibrium monoclinic phase $\left(a=6.86 \AA, b=7.42 \AA, c=4.93 \AA, \beta=102.8^{\circ}\right)$ through a eutectic-type reaction.

Sastry et al (1978) have followed the decomposition of an amorphous Al-6 at. \% Pd alloy. In situ heating revealed that the amorphous phase transformed 
first into a supersaturated solid solution of $\mathrm{Pd}$ in $\mathrm{Al}$ followed by the precipitation of an intermediate phase.

Padhy et al (1979) have examined the crystallisation of $\mathrm{Nb}_{40} \mathrm{Ni}_{60}$ glass. The ribbons, obtained as a courtesy from Dr H A Davies of Sheffield University, UK, were examined in a transmission electron microscope after suitable thinning. The diffraction pattern (figure $8 \mathrm{a}$ ) showed diffuse haloes characteristic of the amorphous state. The ribbons were also examined after heating them for $1 \mathrm{~h}$ at $600^{\circ} \mathrm{C}$, $800^{\circ} \mathrm{C}$ and $1000^{\circ} \mathrm{C}$. Such samples showed a crystalline morphology and their diffraction patterns showed a large number of spots (figure $8 b$ ). Complementary $x$-ray diffraction studies were carried out to index this crystalline phase as a tetragonal structure with $a=11 \cdot 06 \AA$ and $c=26 \cdot 64 \AA$. This appears to be a metastable phase preceding the formation of equilibrium $\mu-\mathrm{NiNb}$ (rhombohedral) and $\mathrm{Ni}_{3} \mathrm{Nb}$ (orthorhombic phases). The route for the change of the metastable to stable phase is presently under detailed study.

\section{Conclusions}

The foregoing account indicates that a modest, but multifaceted beginning has been made at Varanasi to explore the intriguing world of amorphous alloys. An encouraging sign is that other centres in India, viz., Indian Institute of Technologies at Kanpur and Delhi and, Bhabha Atomic Research Centre, Bombay, are also developing interest in this area. It is hoped that Indian contributions to this emerging area in metal sciences will be significant and substantial.

\section{Acknowledgements}

The authors are extremely grateful to their colleagues Drs C Suryanarayana, S Lele, K Chattopadhyay, T K G Namboodhiri, V Singh and O N Srivastava for stimulating discussions and permission to quote from their unpublished results. Cooperation from Professors S L Malhotra, P Rama Rao and P Krishna is also acknowledged. Thanks are due to the Department of Science and Technology, Government of India, for generous financial support.

\section{References}

Anantharaman T R 1979 Trans. Indian Inst. Met. 3212 zii

Anantharaman T R 1979 Keynote Lecture at the Tenth National Conference on Crystallography (to be published)

Anantharaman T R, Ramachandrarao P, Suryanarayana C, Lele S and Chattopadhyay K, 1977 Trans. Indian Inst. Met. 30423

Anantharaman T R, Ramachandrarao P, Suryanarayana C, Lele S, Chattopadhyay K, Sastry G V S and Davies H A 1978 in Rapidly quenched metals ed. B Cantor (London : Metals Society) 1126

Ashby M F, Spaepen F and Williams S 1978 Acta Metallur. 261647

Bernal J D 1964 Proc. Roy. Soc. (London) A280 299

Brandon D G, Ralph B, Ranganathan S and Wald M S 1964 Acta Metallur. 12813

Chattopadhyay K, Ramachandrarao P, Lele S and Anantharaman T R 1976 in Rapidly quenched metals eds, N J Grant and B C Giessen (Cambridge : M.I.T, Press) p. 157 
Duwez P 1979 Proc. Indian Acad. Sci. C2 117

Duwez P, Willens R H and Klement W 1960 J. Appl. Phys. 311136

Duwez P and Willens R H 1963 Trans. Met. Soc. AIME 227362

Gokularathnam C V 1974 J. Mater. Sci. 9673

Hubert J C, Mollard F and Lux B 1973 Z. Metallkde. 64835

Maringer R E and Mobley C E 1974 J. Vac. Sci. Technol. 111067

Masumoto T, Hashimoto $\mathrm{K}$ and Naka $\mathrm{H}$ in Rapidly quenched metals (ed.) B Cantor (London : Metals Society) 2435

Nielsen H J V 1979 Z. Metallkde. 70180

Padhy B, Srivastava O N and Ranganathan S 1979 (to be published)

Pietrokowsky P 1963 Rev. Sci. Instr. 34445

Polk D E 1970 Scr. Metall. 4117

Ramachandrarao P 1968 Ph.D. Thesis, Banaras Hindu University

Ramachandrarao P 1978 in Rapid quenched metals ed. B Cantor (London : Metals Society) p. 392

Ramachandrarao P 1979a Trans. Jpn. Inst. Metals (in press)

Ramachandrarao P 1979b Z. Metallkde. (Communicated)

Ramachandrarao P, Banerji D and Anantharaman T R 1970a Met. Trans, 12655

Ramachandrarao P, Garg P K and Anantharaman T R 1970b Indian J. Technol. 8263

Ramachandrarao P, Cantor B and Cahn R W 1977 J. Mater. Sci. 122488

Ramachandrarao P, Lal K, Singhdeo A and Chattopadhyay K 1979 Mater. Sci. Engg. (in press)

Ramineni A P 1978 M.Tech. dissertation, Banaras Hindu University

Ranganathan S 1979 (to be published)

Ranganathan S, Ramachandrarao P and Singh V 1973 Report to Indian National Science Academy

Roy B and Ranganathan S 1976 Trans. Indian Inst. Met. 2962

Sastry G V S, Suryanarayana C, Srivastava O N and Davies H A 1978 Trans. Indian Inst. Met. 31292

Singh V and Namboodhiri T K G N 1979 (to be published)

Singh V, Mishra R and Namboodhiri T K G N 1979 (to be published)

Spaepen F 1978 in Rapidly quenched metals ed. B Cantor (London : Metal Society) 2253 